\title{
Prevalence of byssinosis in textile mills at Ahmedabad, India
}

\author{
J R PARIKH, L J BHAGIA, P K MAJUMDAR, A R SHAH, S K KASHYAP \\ From the National Institute of Occupational Health, Ahmedabad-380 016, India
}

\begin{abstract}
In an epidemiological study carried out in three textile mills at Ahmedabad, India, 929 workers were examined from the spinning departments. The mean prevalence of byssinosis in the blow section was $29.62 \%$, whereas in the card section it was $37.83 \%$. The concentrations of cotton dust (dust less fly) were high in the blow and card sections $\left(4.00 \mathrm{mg} / \mathrm{m}^{3}\right.$ in the blow and $3.06 \mathrm{mg} / \mathrm{m}^{3}$ in the card section). This study suggests that the prevalence of byssinosis is not low in the textile mills of India as reported in many earlier Indian studies.
\end{abstract}

Byssinosis is an occupational lung disease often observed among workers exposed to cotton, flax, and hemp dust. The severity and extent of the problem are well recognised in the developed countries and control measures have been implemented to prevent the disease. This is not true, however, for the developing countries where the severity and extent of the problem are not well studied and preventive measures are virtually non-existent.' In India several studies on byssinosis were undertaken in the past ${ }^{23}$ (and KC Thiruvengadam in 1967 and JR Sen in 1968 at Indian Council of Medical Research, New Delhi). A review of the earlier studies on byssinosis suggests a low prevalence of the disease in most of the Indian textile mills. ${ }^{3}$ Our study in one Ahmedabad textile mill, however, showed a high prevalence of the disease, especially in the blow and card sections of the mill. ${ }^{4}$ The study was extended to two other textile mills in Ahmedabad. The overall findings of the study of three textile mills are presented in the present paper.

\section{Material and methods}

Three textile mills were included in this study. These mills, selected from different areas of Ahmedabad, Gujarat State, India, were using a medium variety of cotton as the raw material and manufactured only cotton cloth. The ventilation was poor in the blow and card sections of these mills. There was no exhaust device over the carding machines.

At the beginning of the study we tried to obtain a list of the workers in the spinning department of each mill to select a sample based on statistical methods, but

Accepted 16 January 1989 none of the managements could give us an exact section list of the workers. Nevertheless, we could obtain the approximate figures for the total (permanent and temporary) number of workers in each mill. There were 530 (480 permanent, 50 temporary) workers in the first mill, 290 (260 permanent, 30 temporary) in the second, and 300 (265 permanent, 35 temporary) in the third. The number of permanent and temporary workers varied slightly on each visit depending on the absence of permanent workers. Since the temporary workers used to get work (badli) for 15-20 days in a month, their exposure was irregular. Therefore, it was decided to exclude them from the study. Thus out of the permanent workers we could examine $452(94 \cdot 17 \%)$ workers from the first mill, $237(91 \cdot 15 \%)$ from the second, and 240 (90.57\%) from the third. Overall, $929(92.44 \%)$ permanent workers were examined out of 1005 workers. From the four sections of spinning department, more than $95 \%$ of the workers were examined from the dusty sections (blow, card, and frame). Only in the ringframe section was the coverage low.

A questionnaire specially designed on the basis of Schilling's recommendations for the diagnosis of byssinosis and the Medical Research Council (UK) questionnaire on chronic bronchitis was used in the study. ${ }^{1}$ The interviews of the workers were arranged on the first day of the week after a weekend break.

Pulmonary function tests were carried out on a vitalograph spirometer. Forced vital capacity (FVC) and forced expiratory volume in one second $\left(\mathrm{FEV}_{1}\right)$ were measured on the first day of the week after a weekend break at the beginning of the shift and after a minimum exposure of seven hours.

The airborne cotton dust samples were collected by a cone sampler. A $2 \mathrm{~mm} \times 2 \mathrm{~mm}$ of wire gauze was 
attached to the face of the cone to prevent the "fly" and thus concentration of cotton dust less fly was measured.

\section{Results}

The permanent workers in the spinning department (blow, card, frame, and ring frame sections) were examined in this study. Table 1 shows the departmental distribution of the workers.

Table 1 Number of workers (exposed to cotton dust) studied in three textile mills

\begin{tabular}{llllll}
\hline \multirow{5}{*}{\begin{tabular}{llllll}
\multicolumn{2}{l}{ Department } \\
\cline { 2 - 6 } No
\end{tabular}} & Blow & Card & Frame & $\begin{array}{l}\text { Ring } \\
\text { frame }\end{array}$ & Total \\
\hline 1 & 16 & 26 & 98 & 312 & 452 \\
2 & 21 & 26 & 54 & 136 & 237 \\
3 & 17 & 22 & 39 & 162 & 240 \\
Total & 54 & 74 & 191 & 610 & 929 \\
\hline
\end{tabular}

Table 2 A summary of studies on prevalence of byssinosis in Indian textile mills

\begin{tabular}{|c|c|c|c|}
\hline \multirow[b]{2}{*}{ Author } & \multirow[b]{2}{*}{ Year } & \multicolumn{2}{|c|}{$\begin{array}{l}\text { Departmental } \\
\text { prevalence (\%) }\end{array}$} \\
\hline & & Blow & Card \\
\hline $\begin{array}{l}\text { Damodaran et al } \\
\text { Raghavan et } \text { al }^{6} \\
\text { Siddhu } \text { et al } \\
\text { Thiruvengadam } \\
\text { Sen } †\end{array}$ & $\begin{array}{l}1962 \\
1964 \\
1966 \\
1967 \\
1968\end{array}$ & $\begin{array}{l}\frac{20}{-} \\
0.99 \\
3.4\end{array}$ & $\begin{array}{l}20 \\
7 \cdot 63 \\
9 \cdot 02 \\
8 \cdot 00 \\
11 \cdot 33 \\
16(\text { Mill 1) }\end{array}$ \\
\hline Kamat $^{2}$ & 1981 & - & 13 (Mill 2) \\
\hline
\end{tabular}

*At Indian Council of Medical Research in 1967.

†At Indian Council of Medical Research in 1968.
The findings of earlier Indian studies on byssinosis $\overline{\bar{z}}$ are summarised in table 2 . The maximum prevalence $\frac{}{3}$ reported is $20 \%$ whereas the minimum is $0.99 \%$.

Table 3 shows the departmental prevalence of byssinosis. The highest prevalence of byssinosis is in $\overrightarrow{\vec{F}}$ the card section $(37.83 \%)$ whereas in the blow section the mean prevalence is lower than the card section $\frac{C}{0}$ $(29.62 \%)$. In the frame section the prevalence is still $\overline{\frac{\omega}{5}}$ lower $(5.75 \%)$, and in the ringframe section it is negligible $(0.65 \%)$.

Table 4 shows the frequency distribution of के different respiratory symptoms of byssinotic subjects. $\overrightarrow{0}$ Chest tightness or breathlessness, or both, on $\overrightarrow{-}$ Monday - that is, on the first day of the week after a $\omega$ weekend break-are found in a higher percentage of $\circ$ byssinotic workers and therefore characterise $\frac{\mathscr{D}}{3}$ byssinosis from other respiratory diseases.

Table 5 shows the distribution of byssinotic subjects in different exposure groups. The maximum number $\overrightarrow{-}$ of cases are observed in exposure groups 16-20 years $\infty$ and 21-25 years but in the subsequent exposure $v$ groups - that is, 25-30 and more than 30 years-the $\triangle$ number of cases of byssinosis decline despite the longer duration of exposure.

The grade analysis of byssinotic subjects shows the maximum number in grade 2 (table 6 ). No case is observed in grade $1 / 2$.

Table 7 shows the relation of smoking to byssinosis, $\vec{\theta}$ although the percentage of byssinotic workers gs 0 higher among the smokers, the chi-squared test is notsignificant at the 0.05 level.

Table 8 shows the mean change in $\mathrm{FEV}_{1}$ during the shift in the byssinotic and control workers. No controlo group was studied in mill No 3 as it had only a spinningo department. The mean FEV $_{1}$ decline among $59 \stackrel{\varnothing}{\circ}$ byssinotic workers is $\mathbf{0 . 2 5 1}$.

Table 9 shows the time weighted averages of dust $\rightrightarrows$ concentrations (dust less fly). The dust concentrations $\widetilde{ }$ are high in the blow and card sections $\left(4.00 \mathrm{mg} / \mathrm{m}^{3}\right.$ in the blow, $3.06 \mathrm{mg} / \mathrm{m}^{3}$ in the card section).

Table 3 Departmental prevalence of byssinosis in three textile mills at Ahmedabad

\begin{tabular}{|c|c|c|c|c|c|c|c|c|c|c|}
\hline \multirow[b]{2}{*}{ Department } & \multicolumn{3}{|l|}{ Mill I } & \multicolumn{3}{|l|}{ Mill 2} & \multicolumn{3}{|l|}{ Mill 3} & \multirow[b]{2}{*}{$\begin{array}{l}\text { Mean } \\
\text { range }\end{array}$} \\
\hline & $\begin{array}{l}\text { No of } \\
\text { workers } \\
\text { studied }\end{array}$ & $\begin{array}{l}\text { No with } \\
\text { byssinosis }\end{array}$ & $\%$ & $\begin{array}{l}\text { No of } \\
\text { workers } \\
\text { studied }\end{array}$ & $\begin{array}{l}\text { No with } \\
\text { byssinosis }\end{array}$ & $\%$ & $\begin{array}{l}\text { No of } \\
\text { workers } \\
\text { studied }\end{array}$ & $\begin{array}{l}\text { No with } \\
\text { byssinosis }\end{array}$ & $\%$ & \\
\hline Blow & 16 & 3 & $18 \cdot 75$ & 21 & 7 & $33 \cdot 3$ & 17 & 6 & $35 \cdot 29$ & $\begin{array}{r}29.62 \\
(18.75\end{array}$ \\
\hline Card & 26 & 13 & $50 \cdot 00$ & 26 & 7 & 26.92 & 22 & 8 & $36 \cdot 36$ & $\begin{array}{r}37.83 \\
(26.92\end{array}$ \\
\hline Frame & 98 & 6 & $6 \cdot 12$ & 54 & 1 & 1.85 & 39 & 4 & $10 \cdot 25$ & $\begin{array}{r}5.75 \\
(1.85\end{array}$ \\
\hline Ringframe & 312 & 1 & $0 \cdot 32$ & 136 & 3 & $2 \cdot 20$ & 162 & 0 & $0 \cdot 0$ & $\begin{array}{l}0.65 \\
(0.00\end{array}$ \\
\hline Total & 452 & 23 & 5.08 & 237 & 18 & $7 \cdot 59$ & 240 & 18 & $7 \cdot 50$ & $\begin{array}{r}6.35 \\
(5.08 \\
\end{array}$ \\
\hline
\end{tabular}


Table 4 Frequency distribution of different respiratory symptoms in byssinotic subjects of the three mills. (Figures in parentheses indicate percentage)

\begin{tabular}{|c|c|c|c|c|c|c|}
\hline \multirow[b]{2}{*}{$\begin{array}{l}\text { Mill } \\
\text { No }\end{array}$} & \multirow[b]{2}{*}{$\begin{array}{l}\text { No of byssinotic } \\
\text { subjects }\end{array}$} & \multicolumn{5}{|l|}{ Symptoms } \\
\hline & & $\begin{array}{l}\text { Chest } \\
\text { tightness }\end{array}$ & Breathlessness & $\begin{array}{l}\text { Monday } \\
\text { sickness }\end{array}$ & Cough & $\begin{array}{l}\text { Cough with } \\
\text { expectoration }\end{array}$ \\
\hline $\begin{array}{l}1 \\
2 \\
3\end{array}$ & $\begin{array}{l}23 \\
18 \\
18\end{array}$ & $\begin{array}{l}21(91 \cdot 3) \\
18(100 \cdot 0) \\
16(88 \cdot 8)\end{array}$ & $\begin{array}{l}13(56 \cdot 5) \\
17(94 \cdot 4) \\
17(94.4)\end{array}$ & $\begin{array}{l}22(95 \cdot 6) \\
18(100 \cdot 0) \\
18(100 \cdot 0)\end{array}$ & $\begin{array}{l}14(60 \cdot 8) \\
14(77 \cdot 7) \\
12(66 \cdot 6)\end{array}$ & $\begin{array}{r}12(52 \cdot 1) \\
6(33 \cdot 3) \\
4(22 \cdot 2)\end{array}$ \\
\hline
\end{tabular}

Table 5 Distribution of byssinotic cases according to the duration of exposure

\begin{tabular}{|c|c|c|c|c|c|c|}
\hline \multirow[b]{2}{*}{ Exposure group (y) } & \multicolumn{3}{|c|}{ Mill No } & \multirow[b]{2}{*}{ Total No } & \multirow[b]{2}{*}{ No of byssinotic cases } & \multirow[b]{2}{*}{$\%$} \\
\hline & 1 & 2 & 3 & & & \\
\hline $\begin{array}{l}0-5 \\
6-10 \\
11-15 \\
16-20 \\
21-25 \\
26-30 \\
>30\end{array}$ & $\begin{array}{r}39 \\
134 \\
45 \\
51 \\
57 \\
55 \\
71\end{array}$ & $\begin{array}{r}3 \\
67 \\
57 \\
48 \\
24 \\
15 \\
23\end{array}$ & $\begin{array}{r}7 \\
46 \\
68 \\
46 \\
32 \\
26 \\
15\end{array}$ & $\begin{array}{r}49 \\
247 \\
170 \\
145 \\
113 \\
96 \\
109\end{array}$ & $\begin{array}{r}1 \\
11 \\
9 \\
16 \\
13 \\
6 \\
3\end{array}$ & $\begin{array}{r}2.04 \\
7.48 \\
5.29 \\
11.03 \\
11.50 \\
6.25 \\
2.75\end{array}$ \\
\hline
\end{tabular}

Table 6 Gradewise analysis of byssinotic subjects

\begin{tabular}{lcccc}
\hline & \multicolumn{3}{l}{ No of byssinotic subjects } & \\
\cline { 2 - 4 } Grade of byssinosis & Mill I & Mill 2 & Mill 3 & Total \\
\hline Grade 1/2 & 0 & 0 & 0 & 0 \\
Grade 1 & 6 & 5 & 2 & 13 \\
Grade 2 & 14 & 13 & 15 & 42 \\
Grade 3 & 3 & 0 & 1 & 4 \\
Total & 23 & 18 & 18 & 59 \\
\hline
\end{tabular}

Table 7 Relation of smoking to byssinosis

\begin{tabular}{lccc}
\hline Subjects & Smoker & Non-smoker & Total \\
\hline Byssinotic & 40 & 19 & 59 \\
Non-byssinotic & 535 & 335 & 870 \\
Total & 575 & 354 & 929 \\
\hline
\end{tabular}

Chi-squared test $=$ Non-significant at 0.05 level.

Table 8 Mean change in FEV, during the shift in byssinotic and control workers. (Figures in parentheses indicate number of subjects examined)

\begin{tabular}{lll}
\hline \multirow{2}{*}{ Mill No } & \multicolumn{2}{c}{ Mean difference in $F E V_{1}(l)$ during shift } \\
\cline { 2 - 3 } & Byssinotic workers & Control workers \\
\hline 1 & $-0.29(21)$ & $-0.01(96)$ \\
2 & $-0.18(17)$ & $+0.01(91)$ \\
\hline
\end{tabular}

Table 9 Mean cotton dust concentrations (dustless fly $\mathrm{mg} / \mathrm{m}^{3}$ ) in the different departments of three textile mills

\begin{tabular}{lllll}
\hline Department & Mill I & Mill 2 & Mill 3 & Mean \\
\hline Blow & 3.76 & 4.82 & 3.88 & 4.00 \\
Card & 3.72 & 2.33 & 3.12 & 3.06 \\
Frame & 1.45 & 1.12 & 1.04 & 1.16 \\
Ringframe & 1.29 & 1.45 & 1.77 & 1.50 \\
\hline
\end{tabular}

\section{Discussion}

In India several researchers have studied the problem of byssinosis. Their findings are summarised in table 2 . These studies suggest a low prevalence of byssinosis in most of the mills. These observations are surprising because the textile industry had existed for more than a century in India with old machinery and without any dust control devices. By contrast with these findings, researchers in other countries have observed a high prevalence of the disease. For instance, El Batawi et al observed a prevalence of $27 \%$ in card rooms ${ }^{8}$ whereas Molyneux and Tombleson found a prevalence of $24 \%$ in blow rooms and $36.8 \%$ in card rooms. ${ }^{9}$ Our present study of three Ahmedabad textile mills shows a mean prevalence of $29.62 \%$ in the blow section and $37.83 \%$ in the card section. Thus our observations are almost similar to the observations of El Batawi and Molyneux and Tombleson. ${ }^{89}$ Since our observations are on a survivor population, the actual prevalence may be higher than reported here. We think that the lower prevalence reported earlier by other researchers in 
India was largely due to confusion of clinical signs of byssinosis such as the occurrence of chest tightness or breathlessness, or both, on the first day of the week. We have observed that chest tightness and breathlessness are present on the first day of the week in most byssinotic workers (table 5) and therefore they are cardinal symptoms of byssinosis. To elucidate these signs, however, special care is required by the interviewer. We recommend that the interview of the textile workers should be arranged only on the first day of the week after an exposure of five to seven hours. In our experience if the interview is arranged on the other days of the week, most workers fail to report the Monday chest tightness and breathlessness. This might be the reason for the lower prevalence reported in many earlier Indian studies.

The findings of this study refer only to the textile mills using a medium variety of cotton. The prevalence of byssinosis might be more in mills using coarse cotton as reported by Roach and Schilling ${ }^{10}$ and Molyneux et al. ${ }^{9}$ An epidemiological study is required to support this view, however.

Generally, with longer duration of exposure, the prevalence of byssinosis increases." In the present study, however, the prevalence has increased up to 25 years of exposure (table 5) but thereafter it declines, probably because some of the byssinotic workers prematurely retire owing to respiratory disability.

In our study we have not seen any case of grade $1 / 2$ byssinosis (table 6). Since chest discomfort is occasional in grade $1 / 2$, the workers may not notice it carefully or neglect it as it is mild in nature.

There is some evidence that byssinotic symptoms are more prevalent among smokers compared with non-smokers. ${ }^{11-13}$ We also observed a higher percentage of byssinotic workers among smokers $(6.96 \%$ among smokers and 5.37\% among non-smokers). Statistically, however, our results are non-significant (table 7). This observation is similar to the observation of Khogali ${ }^{14}$ and Mohamed et al ${ }^{15}$ and suggests that the cotton dust has a more powerful independent effect than smoking.

Zuskin and Valic described a mean decline in FEV of $250 \mathrm{ml}$ and $245 \mathrm{ml}$ in two groups of byssinotic workers. ${ }^{16}$ Although the individual observation of mean decline in $\mathrm{FEV}_{1}$ during the shift of each mill varies to some extent from their observation (table 8), the overall decline in mean $\mathrm{FEV}_{1}(249 \mathrm{ml})$ agrees with their observation.

The concentrations of dust less fly were high in all three mills (table 9) compared with the recommendations of $0.5 \mathrm{mg} / \mathrm{m}^{3}$ by the British Occupational Hygiene Society. ${ }^{17}$ The time weighted averages were much higher in the blow section compared with the card section, whereas the mean prevalence was lower in the blow section than the card section (table 3). This may be due to frequent movement of workers away from the blowing machine where dust is generated whereas in the card section the machines are placed close to each other and the workers generally work $\bar{\alpha}$ near the carding machines most of the time.

In summary, this study has confirmed that the $\frac{\mathbb{\Phi}}{2}$ prevalence of byssinosis in the blow and card sections? of textile mills using medium variety of cotton is not as $\frac{\overrightarrow{\bar{S}}}{\overrightarrow{7}}$ low as reported in many earlier Indian studies and the cotton dust concentrations are high in the blow and card sections of textile mills and need urgent reduction to prevent further incidence of byssinosis.

We are grateful to the management of all three mills who provided the facilities to conduct this study and $\overrightarrow{0}$ also the workers whose cooperation made this study $\overrightarrow{-}$ possible. We acknowledge the help of our technical $\tilde{\sigma}_{\mathcal{O}}$ staff especially Mr M D Patel, Mr Mukesh Vakharia, $\triangle$ and $\mathrm{Mr} \mathrm{H}$ M Patel who have worked throughout the $\frac{\Phi}{3}$ project.

\section{References}

1 Schilling RSF Worldwide problems of byssinosis Chest 1981; 79:3-5S.

2 Kamat SR, Kamat GR, Salpekar VY, Lobo E. Distinguishing byssinosis from chronic obstructive pulmonary disease. Am Rev Respir Dis 1981;124:31-40.

3 Gupta MN. Review of byssinosis in India. Indian J Med Res 1969; 57:1776-89.

4 Parikh JR, Chatterjee BB, Mohan Rao N, Bhagia LJ. The clinical Фุ manifestations of byssinosis in Indian textile workers. $J$ Soc Occup Med 1986;36:24-8.

5 Damodaran VN, Gupta SN, Vishwanathan R. Report of tete enquiry on byssinosis in cotton textile workers. (Official publication.) Vol 4. Delhi: Indian Association for Chest Diseases arid VP Chest Institute, University of Delhi, 1962:36.

6 Raghavan P, Nagendra AS, Thaker PV. Byssinosis and lung capacities in textile workers in Bombay. Indian $J$ Chest Dis $1964 ; 6: 38-47$

7 Siddhu CMS, Kedar N, Mehrotra RK. Byssinosis amongst cotton 을 and jute workers in Kanpur. Indian J Med Res 1966;54:980-94. $\overrightarrow{\bar{C}}$

8 El Batawi MA, Schilling RSF, Valic F, Walford J. Byssinosis in 윽 Egyptian cotton industry: change in ventilatory capacity during the day. Br J Ind Med 1964;21:13-9.

9 Molyneux MKB, Tombleson JBL. An epidemiological study of respiratory symptoms in Lancashire mills, 1963-1966. Br J Ind Med 1970;27:225-34.

10 Roach SA, Schilling RSF. A clinical and environmental study of byssinosis in the Lancashire cotton industry. Br J Ind Med 1960; 17:1-9.

11 Fox AJ, Tombleson JBL, Watt A, Wilkie AG. A survey of respiratory disease in cotton operatives. Part I. Symptoms and $ᄋ$ ventilation test results. $\mathrm{Br} J$ Ind $\mathrm{Med}$ 1973;30:42-7.

12 Merchant JA, Lumsden JC, Kilburn KH, et al. Dose-response 0 studies in cotton textile workers. J Occup Med 1973;15:222-30.

13 Berry G, Molyneux MKB, Tombleson JBL. Relationship between $\frac{D}{D}$ dust levels and byssinosis and bronchitis in Lancashire cotton 을 mills. Br J Ind Med 1974;31:18-27.

14 Khogali M. Byssinosis: a follow-up study of cotton ginnery workers in the Sudan. Br J Ind Med 1976;33:166-74.

15 Mohamed A, El Karim A, Osman Y, Yousif A, El Haimi A. S Byssinosis: environmental and respiratory symptoms among $\mathbf{W}$ textile workers in Sudan. Int Arch Occup Environ Health 1986; $\underset{<}{\sigma}$
57:101-8.

16 Zuskin E, Valic F. Respiratory symptoms and ventilatory function $\frac{e}{E}$ changes in relation to length of exposure to cotton dust. Thorax 1972;27:454-8.

17 British Occupational Hygiene Society Committee on Hygiene Standards. Sub-committee on vegetable textile dusts. Hygiene Standards for cotton dust. Ann Occup Hyg 1972;15:165-92. 